\title{
Protective role of L-methionine against free radical damage of rat brain synaptosomes
}

\author{
Vyacheslav S. Slyshenkov ${ }^{1 凶}$, Anna A. Shevalye ${ }^{1}$, Anton V. Liopo ${ }^{1}$ and Lech Wojtczak ${ }^{2}$ \\ ${ }^{1}$ Institute of Biochemistry, National Academy of Sciences of Belarus, Grodno, Belarus; and \\ ${ }^{2}$ Nencki Institute of Experimental Biology, Warszawa, Poland
}

Received: 12 November, 2002; accepted: 02 December, 20002

Key words: synaptosomes, $\left(\mathrm{Na}^{+}, \mathrm{K}^{+}\right)$-ATPase, L-methionine, tert-butylhydroperoxide, oxygen free radicals, brain

\begin{abstract}
Incubation of rat brain synaptosomal/mitochondrial fraction with tert-butylhydroperoxide resulted in accumulation of the lipid peroxidation product, conjugated dienes, damage of the synaptosomal membrane as evidenced by leakage of lactate dehydrogenase, and decrease of the total content of glutathione and of the GSH/GSSG ratio. This treatment also produced a considerable decrease of the ouabain-sensitive ATPase activity and a much smaller diminution of the activities of glutathione reductase and glutathione transferase. Preincubation of the synaptosomal/mitochondrial fraction with 0.5 or $1.0 \mathrm{mM}$ L-methionine significantly protected against lipid peroxidation, membrane damage and changes in the glutathione system produced by low $(1 \mathrm{mM})$ concentrations of tert-butylhydroperoxide and completely prevented inactivation of ouabain-sensitive ATPase, glutathione reductase and glutathione transferase by such treatment. The importance of L-methionine in antioxidant protection is discussed.
\end{abstract}

Changes in the glutathione system and impairments of sodium and potassium transport are essential factors of brain tissue disturbance in various kinds of oxidative injury in the central nervous system such as Parkinson's and Alzheimer's diseases, ischaemia and reperfusion syndrome (Jenner, 1998; Draczynska-Lusiak et al., 1998; Zeevalk et al., 1998; Urano et al., 1998; Canals et al., 2001;
Keelan et al., 2001). The glutathione system is responsible for neutralization of peroxides and maintenance of protein thiols in the reduced state (Cardoso et al., 1998; Pocernich et $a l ., 2000)$. It is well known that neurons become more vulnerable to oxidative damages after a decrease in reduced glutathione content (Shukitt-Hale et al., 1998). Studies on the glutathione system and sodium and potas-

\footnotetext{
${ }^{\otimes}$ Correspondence and requests for reprints should be addressed to: Vyacheslav S. Slyshenkov, Institute of Biochemistry, National Academy of Sciences of Belarus, 50 BLK, 230009 Grodno, Belarus; fax: +375 152334 121, e-mail: slysz@tut.by
}

Abbreviation: TBH, tert-butylhydroperoxide. 
sium ion transport under oxidative stress conditions make it possible (i) to understand the biochemical impairments occurring in the central nervous system and accompanying damages of the neurons, (ii) to study the ways of stabilization of the systems involved, which can be useful in the therapy of neurological diseases. The present approach is justified by the poor efficiency of traditional antioxidants in protecting the central nervous system against damage by free radicals.

We presumed that L-methionine may appear a positive modulator of the nervous system under oxidative stress conditions. This choice was made because this compound is an essential amino acid, necessary for the maintenance of nitrogen balance and growth of the organism and important for remethylation processes. L-Methionine neutralizes various toxic products by methylation and transsulphonation. Its lipotropic effect is related to its participation in choline synthesis. However, the interest in the antioxidative properties of this amino acid has started only recently (Bagchi et al., 1998; De La Cruz et al., 2000; Villalobos et al., 2000).

The purpose of the present work was to study the effect of a free radical inducer, tert-butylhydroperoxide (TBH), on isolated nerve endings (synaptosomes) and to determine the possible protective properties of L-methionine.

\section{MATERIALS AND METHODS}

Biological material and treatment. The synaptosome-enriched fraction (called throughout as the synaptosomal/mitochondrial fraction) was obtained from large hemispheres of rat brain essentially according to the procedure of Weiler et al. (1981) as described previously (Chumakova \& Liopo, 1996). In brief, albino rats (140-160 g) were killed by decapitation, the brains were quickly removed, the large hemispheres separated free of other fragments of the nervous system and immediately placed in ice-cold isolation medium composed of $320 \mathrm{mM}$ sucrose, 0.5 $\mathrm{mM}$ EDTA and $10 \mathrm{mM}$ Tris/HCl (pH 7.4). After washing in this medium, the hemispheres were homogenized in the same cold medium, followed by centrifugation for $10 \mathrm{~min}$ at 1000 $\times \boldsymbol{g}$. The pellet was discarded and the supernatant was centrifuged for $20 \mathrm{~min}$ at $17000 \times$ $g$. The resulting pellet was suspended in the same medium and was used throughout.

Exposure of the synaptosome-enriched fraction to oxidative stress was performed by suspending aliquots of the particles containing $0.6 \mathrm{mg}$ protein in $0.5 \mathrm{ml}$ of saline medium $(150 \mathrm{mM} \mathrm{NaCl}, 5 \mathrm{mM} \mathrm{KCl}$ and $10 \mathrm{mM}$ Tris $/ \mathrm{HCl}, \mathrm{pH}$ 7.4) and incubating for $30 \mathrm{~min}$ at $37^{\circ} \mathrm{C}$ with various concentrations of $\mathrm{TBH}$. To examine the protective effect of L-methionine the particles were first preincubated with this amino acid for $30 \mathrm{~min}$ in the same medium and at the same temperature. Thereafter, the particles were sedimented by centrifugation for $3 \mathrm{~min}$ at $4000 \times \mathrm{g}$, resuspended in the same medium and analysed as specified or incubated with TBH as indicate above.

Damage to the synaptosomal membrane was assessed by measuring the leakage of lactate dehydrogenase determined from the rate of NADH oxidation by pyruvate (Vasault, 1983). The total activity of lactate dehydrogenase was determined by lysing these particles in $0.2 \%$ Triton $\mathrm{X}-100$.

Analytical procedures. Conjugated dienes were determined in heptane extracts at $235 \mathrm{~nm}$ (Recknagel \& Ghoshal 1966). Reduced (GSH) and oxidized (GSSG) glutathione were measured enzymatically with methylglyoxal in the presence of glyoxalase and with NADPH in the presence of glutathione reductase, respectively (Akerboom \& Sies, 1981). Protein thiol and disulphide groups were determined with the Ellman reagent [5,5'-dithio-bis-(2-nitrobenzoic acid)], which forms colour complexes with - $\mathrm{SH}$ groups at $\mathrm{pH} 8.0$ and with -SS- groups at $\mathrm{pH}$ 10.5, with maximum absorbance at $412 \mathrm{~nm}$ (Robyt et al., 1971). 
Determination of enzyme activities. Catalase activity was determined by the rate of $\mathrm{H}_{2} \mathrm{O}_{2}$ degradation recorded at $240 \mathrm{~nm}$ (Aebi, 1984). Glutathione reductase activity was measured by the rate of NADPH oxidation by oxidized glutathione (Carlberg \& Mannervik, 1985). The assay for glutathione peroxidase was performed by measuring the formation of oxidized glutathione in a reaction between reduced glutathione and tert-butylhydroperoxide (Flohé \& Günzler, 1984). Glutathione transferase activity was determined using reduced glutathione and 1-chloro-2,4-dinitrobenzene as substrates (Rice-Evans et al., 1991). $\left(\mathrm{Na}^{+}, \mathrm{K}^{+}\right.$)-ATPase was measured by determination of ouabain-sensitive liberation of inorganic phosphate (Foley, 1997).

Reagents. Glutathione reductase, glyoxalase, methylglyoxal, L-methionine, 5,5'-dithio-bis-(2-nitrobenzoic acid), tert-butylhydroperoxide, ATP and ouabain were from Sigma (St. Louis, MO, U.S.A.); NADH and $\mathrm{NADPH}$ were from Boehringer (Mannheim, Germany); NADP and lactate dehydrogenase were from Reanal (Budapest, Hungary).

Statistics. The results are presented as mean values \pm standard deviation (S.D.) for at least five experiments. Statistical significance was assessed using the Student's $t$-test, and the difference was admitted as significant at $P \leq 0.05$.

\section{RESULTS}

\section{Effects of tert-butylhydroperoxide}

Treatment of the synaptosomal/mitochondrial fraction with TBH produced typical features of an oxidative stress. The effects were concentration-dependent. Lipid peroxidation, determined as accumulation of conjugated dienes, is illustrated in Fig. 1 and the oxidative shift of the glutathione system is shown in Fig. 2. As can be calculated from the data of Fig. 2 (see also Table 1), the GSH/GSSG ratio decreased from the control value of 9.9 to 3.2

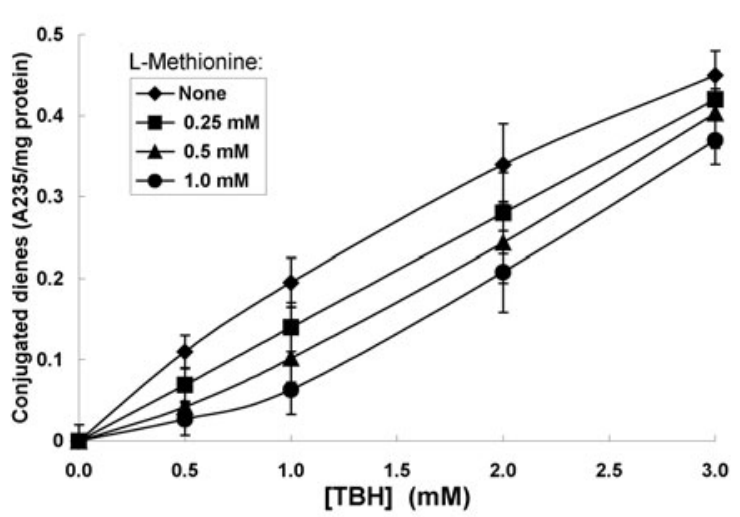

Figure 1. Effect of preincubation with L-methionine on the production of conjugated dienes in the synaptosomal/mitochondrial fraction under treatment with TBH.

The particles were preincubated with different concentrations of L-methionine, followed by incubation with various concentrations of TBH as described under Materials and Methods, and the production of conjugated dienes was determined.

after incubation with $1 \mathrm{mM}$ TBH and to 0.9 after incubation with $3 \mathrm{mM}$ TBH. It can also be seen that the total amount of glutathione decreased as well. Its content, calculated as GSH $+2 \times$ GSSG, decreased from $7.2 \mathrm{nmol} / \mathrm{mg}$ protein in the untreated preparations to 4.6 and $3.6 \mathrm{nmol} / \mathrm{mg}$ protein following $30 \mathrm{~min}$ incubation with 1 and $3 \mathrm{mM} \mathrm{TBH}$, respectively.

Ouabain-sensitive ATPase appeared to be very sensitive to TBH. Its activity decreased below $50 \%$ after incubation with $1 \mathrm{mM} \mathrm{TBH}$ (Fig. 3). A similar decrease was observed in

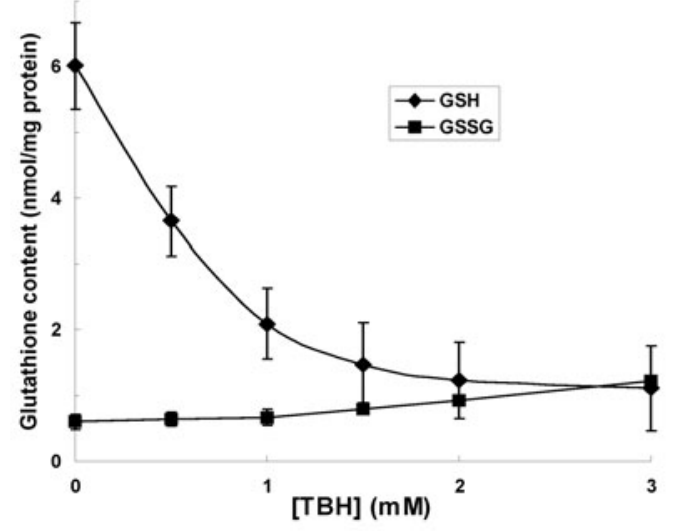

Figure 2. Effect of TBH on the content of reduced and oxidized glutathione in the synaptosomal/mitochondrial fraction. 
Table 1. Effect of L-methionine and TBH on glutathione content and its redox state in the synaptosomal/mitochondrial fraction.

The particles were incubated with L-methionine and TBH as described under Materials and Methods. Control samples were incubated without these additions. Glutathione content is expressed in nmol/mg protein. Statistical significance: *, $P \leq 0.05$ compared to control samples; \#, $P \leq 0.05$ compared to particles treated with TBH only.

\begin{tabular}{llllc}
\hline & GSH & GSSG & $\begin{array}{l}\text { GSH }+ \\
2 \times \text { GSSG }\end{array}$ & GSH/GSSG \\
\hline Control & $6.01 \pm 0.32$ & $0.61 \pm 0.03$ & $7.23 \pm 0.35$ & $9.92 \pm 0.51$ \\
$0.5 \mathrm{mM}$ L-methionine & $7.47 \pm 0.41^{*}$ & $0.40 \pm 0.04^{*}$ & $8.27 \pm 0.41$ & $18.19 \pm 0.92^{*}$ \\
$1.0 \mathrm{mM}$ L-methionine & $7.43 \pm 0.52^{*}$ & $0.31 \pm 0.03^{*}$ & $8.05 \pm 0.43$ & $22.63 \pm 0.95^{*}$ \\
$1.0 \mathrm{mM}$ TBH & $2.81 \pm 0.21^{*}$ & $0.91 \pm 0.04^{*}$ & $4.63 \pm 0.47^{*}$ & $3.16 \pm 0.25^{*}$ \\
$\begin{array}{l}\text { 0.5 mM L-methionine } \\
+1.0 \mathrm{mM} \text { TGH }\end{array}$ & $3.72 \pm 0.22^{*} \#$ & $0.66 \pm 0.05 \#$ & $5.04 \pm 0.45^{*}$ & $5.58 \pm 0.32^{*} \#$ \\
$\begin{array}{l}1.0 \mathrm{mM} \text { L-methionine } \\
+1.0 \mathrm{mM} \text { TBH }\end{array}$ & $3.73 \pm 0.22^{*} \#$ & $0.40 \pm 0.04^{*} \#$ & $4.53 \pm 0.38^{*}$ & $9.28 \pm 0.42 \#$ \\
\hline
\end{tabular}

the content of protein thiol groups (Fig. 3), whereas the intactness of the synaptosomal membrane as evaluated from the leakiness of lactate dehydrogenase was increased by about $15 \%$ (Fig. 4). The activity of glutathione peroxidase was not changed after preincubation of the particle seven with $3 \mathrm{mM} \mathrm{TBH}$, whereas the activities of glutathione transferase and glutathione reductase were significantly decreased (Fig. 5).

\section{Effects of L-methionine}

Preincubation of the synaptosomal/mitochondrial fraction with L-methionine considerably protected against lipid peroxidation by TBH. The strongest protective effect was observed against 0.5 and $1.0 \mathrm{mM}$ TBH, whereas the protection against higher TBH concentrations was less pronounced (Fig. 1). L-Methionine also decreased the leakage of lactate dehydrogenase induced by $1 \mathrm{mM}$ TBH from $16 \%$ to less than $9 \%$ (Fig. 4 ).

L-Methionine alone increased the reduction level of glutathione and slightly but not significantly increased the total glutathione content in the synaptosomal/mitochondrial fraction (Table 1). When the preincubation with L-methionine was followed by incubation with
TBH, a significant protective effect against the damage to the glutathione system was observed. The GSH/GSSG ratio was almost completely restored by $1 \mathrm{mM}$ L-methionine, but the amount of GSH and the total content

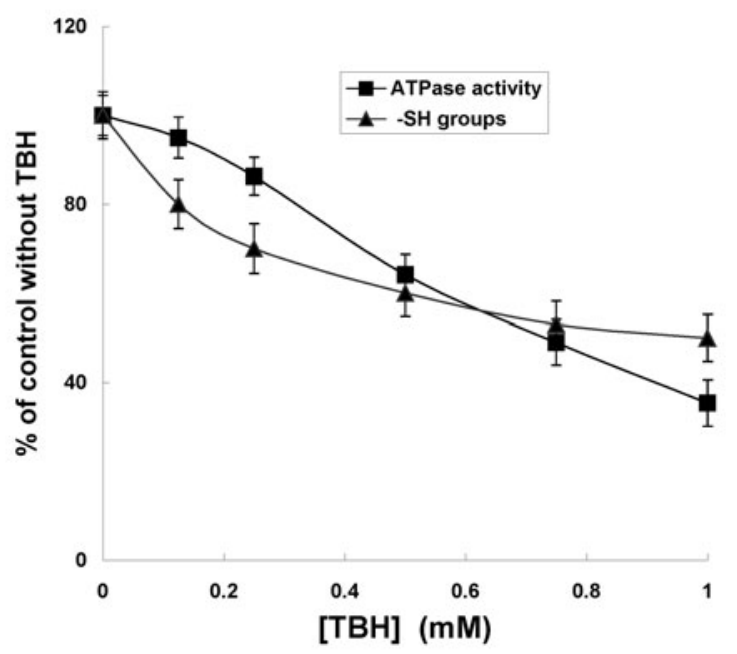

Figure 3. Effect of TBH on the content of -SH groups and the activity of ouabain-sensitive ATPase in the synaptosomal/mitochondrial fractions.

The content of - $\mathrm{SH}$ groups in the particles incubated without TBH (assumed as 100\%) amounted to $50 \pm 2$ $\mathrm{nmol} / \mathrm{mg}$ protein. The control (100\%) activities of ATPase were: total, $5.78 \pm 0.20$; ouabain-insensitive, $4.27 \pm 0.14$; and ouabain-sensitive, $1.52 \pm 0.10 \mu \mathrm{mol} / \mathrm{h}$ per mg protein. 


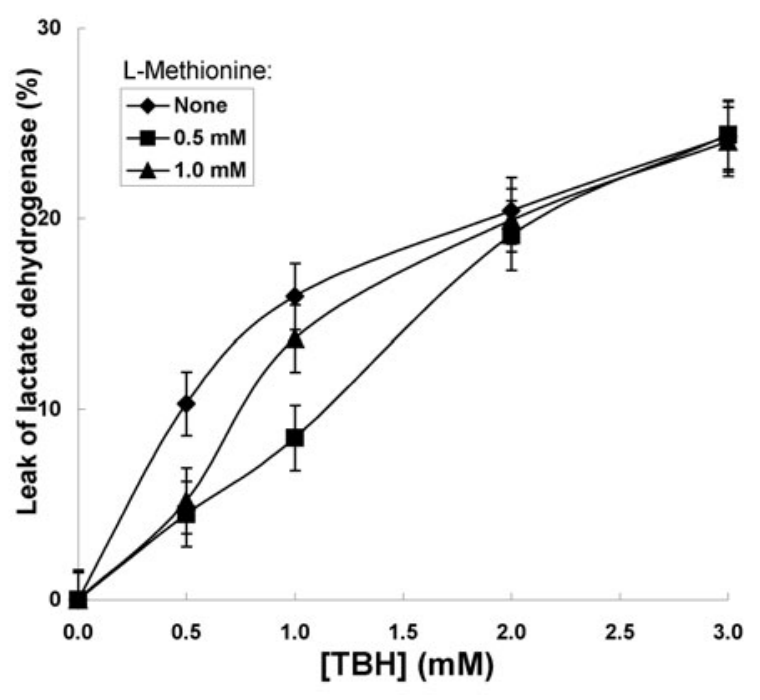

Figure 4. Protective effect of L-methionine against synaptosome damage by TBH treatment.

The synaptosomal/mitochondrial fraction was preincubated for $30 \mathrm{~min}$ without L-methionine or with two concentrations of this amino acid and then for another 30 min with different concentrations of TBH as described under Materials and Methods. Thereafter the particles were sedimented by centrifugation and lactate dehydrogenase activity was determined in the supernatants.

of glutathione were restored only partly (Table 1).

Preincubation with L-methionine appeared to have little effect on the activities of glutathione transferase and glutathione

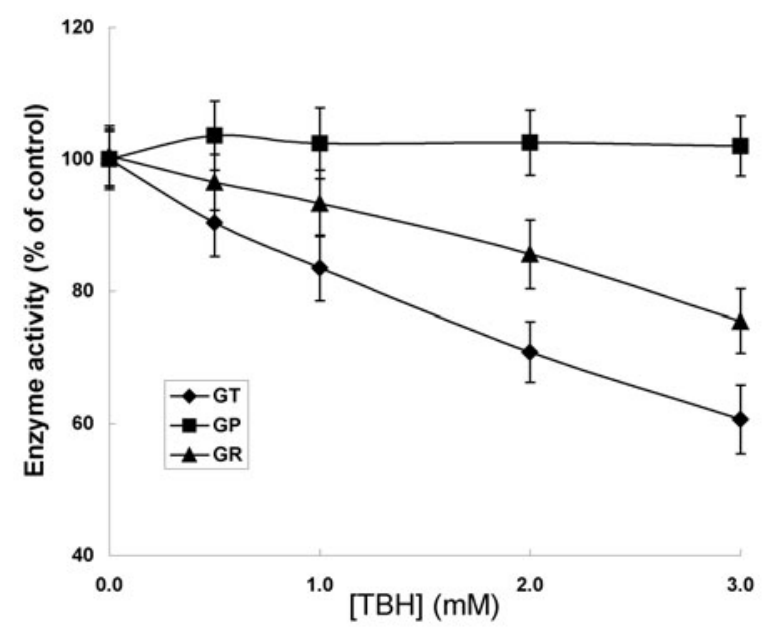

Figure 5. Effect of TBH on the activities of glutathione reductase (GR), glutathione peroxidase (GP) and glutathione transferase (GT) in the synaptosomal/mitochondrial fraction.

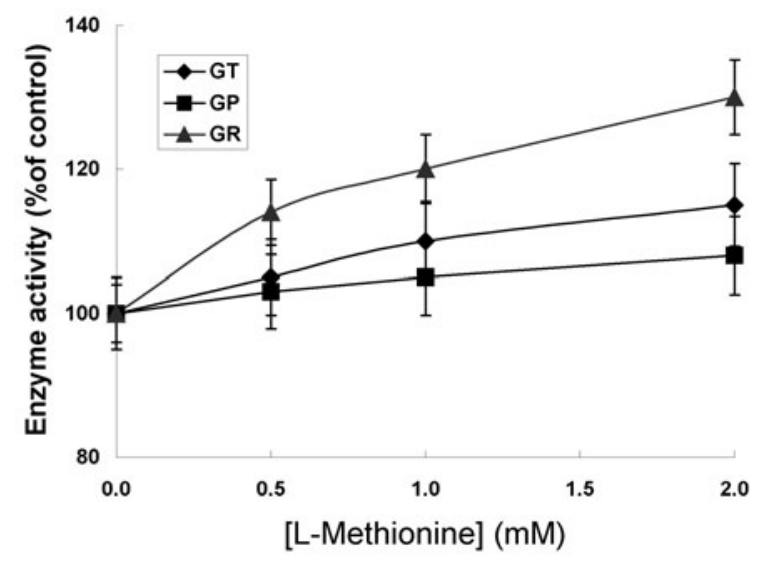

Figure 6. Effect of L-methionine on the activities of glutathione reductase (GR), glutathione peroxidase (GP) and glutathione transferase (GT) in the synaptosomal/mitochondrial fraction.

The experimental protocol was as described under Materials and Methods.

peroxidase and slightly increased the activity of glutathione reductase (Fig. 6). When the biological material was subsequently incubated with $1 \mathrm{mM} \mathrm{TBH}$, preincubation with methionine significantly protected against the partial inactivation of glutathione transferase, augmented the increase of glutathione reductase but did not change the activity of glutathione peroxidase (Fig. 7; for the effect of TBH alone see Fig. 5).

The activity of ouabain-sensitive ATPase was significantly potentiated by L-methionine at concentrations of 0.5 and $1.0 \mathrm{mM}$ (Fig. 8) but decreased after preincubation with concentrations of $2.0 \mathrm{mM}$ and higher (not shown). L-Methionine at 0.5 and $1.0 \mathrm{mM}$ completely protected this enzyme against inactivation by TBH (Fig. 8).

\section{DISCUSSION}

Damaging effects of reactive oxygen species on living systems are well documented. They include oxidative attack on vital cell constituents, such as proteins, lipids and nucleic acids (for reviews see Halliwell \& Gutteridge, 1984; 


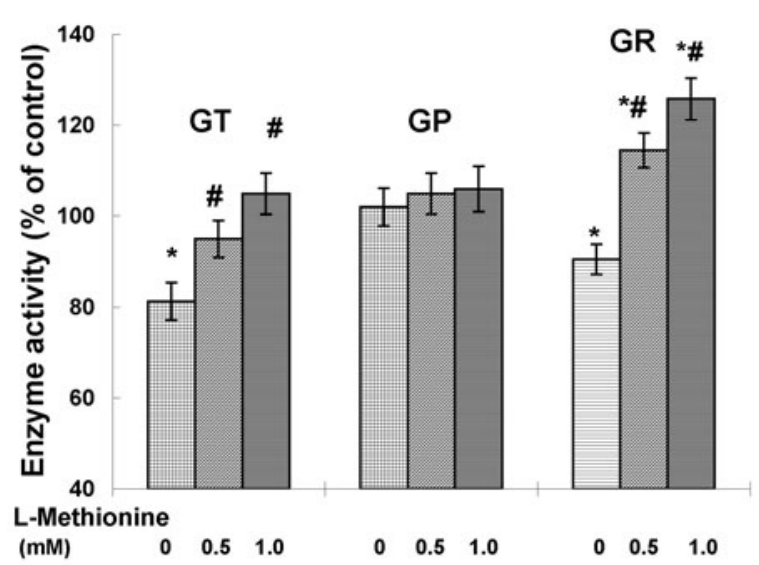

Figure 7. Combined effects of L-methionine and TBH on the activities of glutathione transferase (GT), glutathione peroxidase (GP) and glutathione reductase (GR).

The synaptosomal/mitochondrial fraction was first preincubated without or with L-methionine, followed by incubation with $1.0 \mathrm{mM}$ TBH, as described in Materials and Methods, and the enzyme activities were determined. The values are expressed in percentage of those for the control samples incubated for the same period of time without L-methionine and TBH treatment. Statistical significance: ${ }^{*}, P \leq 0.05$ compared to control samples; \#, $P \leq 0.05$ compared to particles treated with TBH only.

Farber, 1994; Martínez-Cayuela, 1995). In particular, membranous structures and their constituents, membrane-bound enzymes, are prone to oxidative damage. Plasma membrane $\left(\mathrm{Na}^{+}, \mathrm{K}^{+}\right)$-ATPase, whose activity is responsible for maintaining the balance between the major cell cations, $\mathrm{Na}^{+}$and $\mathrm{K}^{+}$, has long attracted attention as a possible target for oxygen free radicals. First reports on the inactivation of membrane-bound $\left(\mathrm{Na}^{+}, \mathrm{K}^{+}\right)$ATPase in erythrocytes by superoxide radicals date from a quarter of a century ago (Bartosz et al., 1977). Subsequent studies have pointed to a high susceptibility of $\left(\mathrm{Na}^{+}, \mathrm{K}^{+}\right)$-ATPase to oxidative inactivation in various tissues (see, e.g., Huang et al., 1992; Reddy \& Bhat, 1999) and, in particular, in brain neurons (Hexum \& Fried, 1979; Arkhipenko et al., 1985; Koide et al., 1986; Palmer, 1987; Asano et al., 1989; Hitschke et al., 1994; Lehotsky et al., 1999). This is in con-
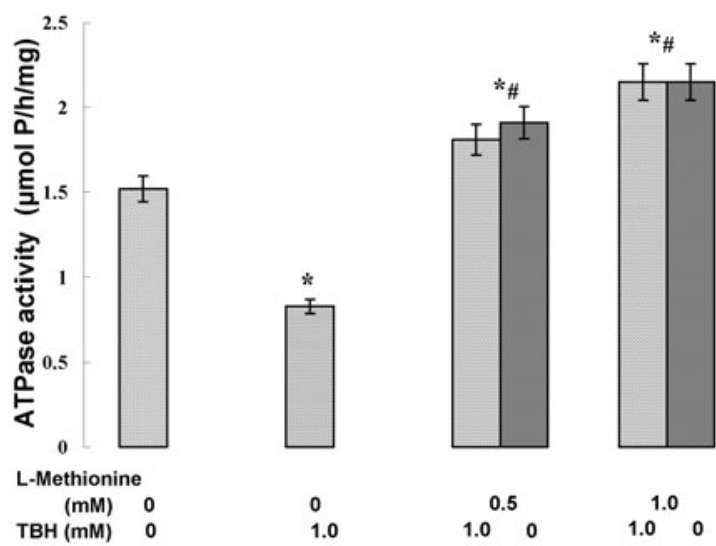

Figure 8. Effects of L-methionine and TBH on the activity of ouabain-sensitive ATPase in the synaptosomal/mitochondrial fraction.

The particles were preincubated for $30 \mathrm{~min}$ with various concentrations of L-methionine and thereafter incubated with $1.0 \mathrm{mM}$ TBH. Statistical significance: *, $P \leq$ 0.05 compared to control samples; \#, $P \leq 0.05$ compared to particles treated with TBH only.

trast to the activation of $\left(\mathrm{Na}^{+}, \mathrm{K}^{+}\right)$-ATPase by oxidative stress in brain microvessels (Koide et al., 1986; Asano et al., 1989), the fact that may contribute to ischaemic evolution of brain edema.

The present results on the rat brain synaptosomal/mitochondrial fraction are fully in line with previous investigations. We confirmed the high susceptibility of synaptosomal $\left(\mathrm{Na}^{+}, \mathrm{K}^{+}\right)$-ATPase to peroxidative inactivation. In fact, after incubation of the particles with $1 \mathrm{mM}$ TBH the activity of $\left(\mathrm{Na}^{+}, \mathrm{K}^{+}\right)$-ATPase was decreased by more than $60 \%$ (Fig. 3), whereas those of glutathione transferase and glutathione reductase by about $15 \%$ and $10 \%$, respectively, and glutathione peroxidase remained unaffected (Fig. 5). The decrease of $\left(\mathrm{Na}^{+}, \mathrm{K}^{+}\right)$-ATPase activity was presumably due to the modification of -SH groups (Fig. 3) as already observed for the brain and kidney enzyme (Iwata et al., 1988). We also observed damage of the brain synaptosomal membrane as manifested by increased leakage of lactate dehydrogenase (Fig. 4), which ran in parallel to the degree of lipid peroxidation, similarly as the previously 
observed damage of the plasma membrane of Ehrlich ascites tumour cells (Slyshenkov et al., 1995; 1996). As expected, incubation of the synaptosomal/mitochondrial fraction with TBH also resulted in drastic changes in the content and the redox state of glutathione. The total content of glutathione that could be determined by the enzymatic procedure employed ("free" glutathione) was decreased by half and the GSH/GSSG ratio to one third of its control value (Table 1 and Fig. 2). This points to an imbalance in the antioxidant defence system.

Apart from cysteine, L-methionine is another amino acid most vulnerable to oxidation (Vogt, 1995; Levine et al., 1996; 1999; Berlett \& Stadtman, 1997). Oxidation of methionine residues to methionine sulphoxide deprives respective proteins of their function as methyl donors and may be responsible for the loss of their biological activity (see, e.g., Carp et al., 1982; Swaim \& Pizzo, 1988; Ciorba et al., 1997). On the other hand, methionine residues can act as powerful antioxidants (Levine et al., 1996). A similar function can presumably be fulfilled by free L-methionine, as documented in the present work. L-Methionine not only partly protected against synaptosomal membrane damage (Fig. 4) and oxidative shift in the glutathione system (Table 1), but also completely prevented decrease of the $\left(\mathrm{Na}^{+}, \mathrm{K}^{+}\right)$-ATPase activity (Fig. 8). It also protected against slight decrease, produced by $\mathrm{TBH}$, in the activities of glutathione transferase and glutathione reductase (Fig. 7). This protective effect was apparently due to an antioxidative mechanism, as manifested by a considerable reduction in the accumulation of lipid peroxidation products (Fig. 1). L-Methionine alone increased the reduction state of glutathione and also increased the total content of this tripeptide (Table 1), which can be interpreted as protection against endogenous peroxidative processes. It is most likely that free L-methionine, that accumulated within synaptosomes and mitochondria during the preincubation, played the protective function, because the short preincubation time and the preincubation conditions, in particular the lack of energy source, were unfavourable for protein synthesis. Nevertheless, it cannot be excluded that some incorporation of methionine into proteins also occurred.

L-Methionine, both free and as a constituent of peptide chains, can be regarded as an excellent biological antioxidant, because its oxidation to methionine sulphoxide is reversible. The latter compound can be reduced back to methionine by methionine sulphoxide reductase, with thioredoxin serving as electron donor (Moskovitz et al., 1999, 2001; Stadtman et al., 2002). Thus, L-methionine, along with the GSH/GSSG system, forms an important link in the antioxidant defence system and contributes to the subtle prooxidant/antioxidant homeostasis within the cell.

The authors wish to thank S. Kirko, O. Andreeva and V. Tayurskaya for their valuable technical assistance.

\section{R E F E R E N C E S}

Aebi H. (1984) Catalase in vitro. Methods Enzymol.; 105: 121-6.

Akerboom TPM, Sies H. (1981) Assay of glutathione, glutathione disulfide, and glutathione mixed disulfides in biological samples. Methods Enzymol.; 77: 373-82.

Arkhipenko YuV, Meerson FZ, Sazontova TG, Kagan VE. (1985) Mode of lipid peroxidation-induced inhibition of Na,K-ATPase. Acta Physiol Pharmacol Bulg.; 11: $70-8$.

Asano T, Koide T, Gotoh O, Joshita H, Hanamura T, Shigeno T, Takakura K. (1989) The role of free radicals and eicosanoids in the pathogenetic mechanism underlying ischemic brain edema. Mol Chem Neuropathol.; 10: 101-33. 
Bagchi D, Vuchetich PJ, Bagchi M, Tran MX, Krohn RL, Ray SD, Stohs SJ. (1998) Protective effects of zinc salts on TPA-induced hepatic and brain lipid peroxidation, glutathione depletion, DNA damage and peritoneal macrophage activation in mice. Gen Pharmacol.; 30: 43-50.

Bartosz G, Fried R, Grzelinska E, Leyko W. (1977) Effect of hyperoxide radicals on bovine-erythrocyte membrane. Eur J Biochem.; 73: 261-4.

Berlett BS, Stadtman ER. (1997) Protein oxidation in aging, disease, and oxidative stress. $J$ Biol Chem.; 272: 20313-6.

Canals S, Casarejos MJ, de Bernardo S, Rodriguez-Martin E, Mena MA. (2001) Glutathione depletion switches nitric oxide neurotrophic effects to cell death in midbrain cultures: implications for Parkinson's disease. J Neurochem.; 79: 1183-95.

Cardoso SM, Pereira C, Oliveira CR. (1998) The protective effect of vitamin $\mathrm{E}$, idebenone and reduced glutathione on free radical mediated injury in rat brain synaptosomes. Biochem Biophys Res Commun.; 246: 703-10.

Carlberg I, Mannervik B. (1985) Glutathione reductase. Methods Enzymol.; 113: 484-90.

Carp H, Miller F, Hoidal JR, Janoff A. (1982) Potential mechanism of emphysema: $\alpha_{1}$-proteinase inhibitor recovered from lungs of cigarette smokers contains oxidized methionine and has decreased elastase inhibitory capacity. Proc Natl Acad Sci U S A.; 79: 2041-5.

Chumakova OV, Liopo AV. (1996) Acetylcholinesterase and choline uptake in striatum from rats with varying sleeping times. Alcohol Alcohol.; 31: 217-20.

Ciorba MA, Heinemann SH, Weissbach H, Brot N, Hoshi T. (1997) Modulation of potassium channel function by methionine oxidation and reduction. Proc Natl Acad Sci U S A.; 94: 9932-7.

De La Cruz JP, Pavia J, Gonzalez-Correa JA, Ortiz P, Sanchez de la Cuesta F. (2000) Effects of chronic administration of $S$-adenosyl-L-methionine on brain oxidative stress in rats. Naunyn Schmiedebergs Arch Pharmacol.; 361: 47-52.

Draczynska-Lusiak B, Doung A, Sun AY. (1998) Oxidized lipoproteins may play a role in neuronal cell death in Alzheimer disease. Mol Chem Neuropathol.; 33: 139-48.

Farber JL. (1994) Mechanisms of cell injury by activated oxygen species. Envir Health Persp.; 102 (Suppl. 10): 17-24.

Flohé L, Günzler WA. (1984) Assays of glutathione peroxidase. Methods Enzymol.; 105: $114-21$.

Foley TD. (1997) 5-HPETE is a potent inhibitor of neuronal $\mathrm{Na}^{+}, \mathrm{K}^{+}$-ATPase activity. Biochem Biophys Res Commun.; 235: 374-6.

Halliwell B, Gutteridge JMC. (1984) Oxygen toxicity, oxygen radicals, transition metals and disease. Biochem J.; 219: 1-14.

Hexum TD, Fried R. (1979) Effects of superoxide radicals on transport $(\mathrm{Na}+\mathrm{K})$ adenosine triphosphatase and protection by superoxide dismutase. Neurochem Res.; 4: $73-82$.

Hitschke K, Bühler R, Apell HJ, Stark G. (1994) Inactivation of the Na,K-ATPase by radiation-induced free radicals. Evidence for a radical-chain mechanism. FEBS Lett.; 353: 297-300.

Huang WH, Wamg Y, Askari A. (1992) $\left(\mathrm{Na}^{+}+\right.$ $\mathrm{K}^{+}$)-ATPase: Inactivation and degradation induced by oxygen radicals. Int $J$ Biochem.; 24: 621-6.

Iwata H, Iwata C, Matsuda T. (1988) Difference between two isozymes of $\left(\mathrm{Na}^{+}+\mathrm{K}^{+}\right)$-ATPase in the interaction with omeprazole. Jpn $J$ Pharmacol.; 46: 35-42.

Jenner P. (1998) Oxidative mechanisms in nigral cell death in Parkinson's disease. Mov Disord.; 1: 24-34.

Keelan J, Allen NJ, Antcliffe D, Pal S, Duchen MR. (2001) Quantitative imaging of glutathione in hippocampal neurons and glia in culture using monochlorobimane. $J$ Neurosci Res.; 66: 873-84.

Koide T, Asano T, Matsushita H, Takakura K. (1986) Enhancement of ATPase activity by a 
lipid peroxide of arachidonic acid in rat brain microvessels. $J$ Neurochem.; 46: 235-42.

Lehotsky J, Kaplan P, Racay P, Matejovicova M, Drgova A, Mezesova V. (1999) Membrane ion transport systems during oxidative stress in rodent brain: protective effect of stobadine and other antioxidants. Life Sci.; 65: 1951-8.

Levine RL, Mosoni L, Berlett BS, Stadtman ER. (1996) Methionine residues as endogenous antioxidants in proteins. Proc Natl Acad Sci U S A.; 93: 15036-40.

Levine RL, Berlett BS, Moskovitz J, Mosoni L, Stadtman ER. (1999) Methionine residues may protect proteins from critical oxidative damage. Mech Ageing Dev.; 107: 323-32.

Martínez-Cayuela M. (1995) Oxygen free radicals and human disease. Biochimie.; 77: 147-61.

Moskovitz J, Berlett BS, Poston JM, Stadtman ER. (1999) Methionine sulfoxide reductase in antioxidant defense. Methods Enzymol.; 300: 239-44.

Moskovitz J, Bar-Noy S, Williams WM, Requena J, Berlett BS, Stadtman ER. (2001) Methionine sulfoxide reductase (MsrA) is a regulator of antioxidant defense and lifespan in mammals. Proc Natl Acad Sci U S A.; 98: 12920-5.

Palmer GC. (1987) Free radicals generated by xanthine oxidase-hypoxanthine damage adenylate cyclase and ATPase in gerbil cerebral cortex. Metab Brain Dis.; 2: 243-57.

Pocernich CB, La Fontaine M, Butterfield DA. (2000) In-vivo glutathione elevation protects against hydroxyl free radical-induced protein oxidation in rat brain. Neurochem Int.; 36: 185-91.

Reddy GB, Bhat KS. (1999) Protection against UVB inactivation (in vitro) of rat lens enzymes by natural antioxidants. $\mathrm{Mol}$ Cell Biochem.; 194: 41-5.

Rice-Evans CA, Diplock AT, Symons MCR. (1991) Techniques in free radical research. Elsevier, Amsterdam.

Robyt JF, Ackerman RJ, Chittenden CG. (1971) Reaction of protein disulfide groups with
Ellman's reagent: a case study of the number of sulfhydryl and disulfide groups in Aspergillus oryzae $\alpha$-amylase, papain and lysozyme. Arch Biochem Biophys.; 147: 262-9.

Shukitt-Hale B, Erat SA, Joseph JA. (1998) Spatial learning and memory deficits induced by dopamine administration with decreased glutathione. Free Radical Biol Med.; 24: 1149-58.

Slyshenkov VS, Rakowska M, Moiseenok AG, Wojtczak L. (1995) Pantothenic acid and its derivatives protect Ehrlich ascites tumor cells against lipid peroxidation. Free Radical Biol Med.; 19: 767-72.

Slyshenkov VS, Moiseenok AG, Wojtczak L. (1996) Noxious effects of oxygen reactive species on energy coupling processes in Ehrlich ascites tumor mitochondria and the protection by pantothenic acid. Free Radical Biol Med.; 20: 793-800.

Stadtman ER, Moskovitz J, Berlett BS, Levine RL. (2002) Cyclic oxidation and reduction of protein methionine residues is an important antioxidant mechanism. Mol Cell Biochem.; 234-235: 3-9.

Swaim MW, Pizzo SV. (1988) Methionine sulfoxide and the oxidative regulation of plasma proteinase inhibitors. J Leukoc Biol.; 43: $365-79$.

Urano S, Sato Y, Otonari T, Makabe S, Suzuki S, Ogata M, Endo T. (1998) Aging and oxidative stress in neurodegeneration. Biofactors.; 7: 103-12.

Vasault A. (1983) Lactate dehydrogenase: UVmethod with pyruvate and NADH. In Methods of enzymatic analysis. Bergmeyer J, Grassl M. eds, 3rd edn., vol 3, pp 118-26. Verlage Chemie, Weinheim.

Villalobos MA, De La Cruz JP, Cuerda MA, Ortiz P, Smith-Agreda JM, Sanchez De La Cuesta F. (2000) Effect of $S$-adenosyl-L-methionine on rat brain oxidative stress damage in a combined model of permanent focal ischemia and global ischemia-reperfusion. Brain Res.; 883: 31-40. 
Vogt W. (1995) Oxidation of methionyl residues in proteins: tools, targets, and reversal. Free Radical Biol Med.; 18: 93-105.

Weiler MH, Gundersen CB, Jenden DJ. (1981) Choline uptake and acetylcholine synthesis in synaptosomes: investigations using two different labeled variants of choline. $J$ Neurochem.; 36: 1802-12.
Zeevalk GD, Bernard LP, Nicklas WJ. (1998) Role of oxidative stress and the glutathione system in loss of dopamine neurons due to impairment of energy metabolism. $J$ Neurochem.; 70: 1421-30. 